\title{
Hubungan kualitas pelayanan posyandu dengan minat kunjungan ibu di posyandu Kemuning XII Desa Cibeber Cilegon
}

\author{
Halimah $\mathrm{T}^{1^{*}}$, Nuria Fitri Adista ${ }^{2}$ \\ 1,2Politeknik Kesehatan Aisyiyah Banten
}

\section{INFORMASI ARTIKEL:}

Riwayat Artikel:

Tanggal diterima, 7 Agustus 2021

Tanggal direvisi, 22 Desember 2021

Tanggal dipublikasi, 30 Desember 2021

\section{Kata kunci:}

Kualitas Pelayanan;

Posyandu;

Minat Kunjungan;

\subsection{6/jrki.v5i2.185}

Keyword :

Service quality;

Posyandu;

Visiting Interest;

\section{Pendahuluan}

Pembangunan Kesehatan merupakan bagian dari pembangunan nasional untuk memwujudkan derajat Kesehatan masyarakat. Arah kebijakan pembangunan Jangka Menengah (RPJM) 20152019 mengacu pada tiga hal yaitu penguatan pelayanan Kesehatan primer, penerapan

\footnotetext{
* Korespondensi penulis.

Alamat E-mail: anonim@mail.com
}

\begin{abstract}
ABSTRAK
Latar belakang: Tingkat kunjungan Ibu hamil dan ibu yang memiliki bayi dan balita di Posyandu Kemuning XII Desa Cibeber Cilegon masih rendah. Kunjungan posyandu hanya sekitar $40 \%$ setiap bulannya dari total jumlah 150 bumil atau ibu yang memiliki bayi dan balita di tahun 2020 dalam pemantauan 3 bulan terakhir, begitu juga pada tahun 2019 . Tujuan penelitian: untuk mengetahui hubungan kualitas pelayanan dengan minat kunjungan ibu di posyandu Kemuning XII Desa Cibeber Cilegon. Metode: Penelitian menggunakan metode analitik dengan rancangan cross sectional. Populasi penelitian adalah semua ibu yang berkunjung ke posyandu Kemuning XII desa cibeber Cilegon kurun waktu Januari- Maret berjumlah 150. Tehnik pengambilan sampel dengan cara accidental sampling. Data yang digunakan adalah data primer dengan Instrumen menggunakan Kuesioner. Data dianalisis dengan menggunakan Chi Square dengan tingkat kesalahan (a $=0,05$ ). Hasil: Sebagian besar responden menyatakan kualitas pelayanan sudah baik sebesar $80,4 \%$, Terdapat responden yang menyatakan kualitas layanan baik dan juga memiliki minat kunjungan baik sebanyak $95,1 \%$. Hasil P Value $=0.000(p=0.000)$. Simpulan: Terdapat hubungan yang bermakna antara kualitas pelayanan dengan minat kunjungan ke Posyandu Kemuning XII Desa Cibeber Cilegon.
\end{abstract}

Background: The visit rate of pregnant women and mothers with babies and toddlers at the Kemuning XII Posyandu, Cibeber Village, Cilegon is still low. Posyandu visits are only about $40 \%$ every month. This number is out of a total of 150 pregnant women or mothers with babies and toddlers in 2020 in the last 3 months of monitoring, as well as in 2019 in that area. Objectives: To determine the correlation between service quality and visiting interest of mothers at Kemuning XII Posyandu, Cibeber Village, Cilegon. Methods: The study used an analytic method with a cross-sectional design. The research population was all mothers who visited the Kemuning XII Posyandu, Cibeber Village, Cilegon, from January to March, amounting to 150. The sampling technique was accidental sampling. The data used were primary data with the instrument using a questionnaire. Data were analyzed using Chi-Square with an error rate $(a=0.05)$. Results: Most of the respondents stated that the service quality was good at $80.4 \%$, some respondents stated the good service quality and good interest in visiting as many as $95.1 \%$. Result $P$ Value $=0.000$ $(p=0.000)$. Conclusion: There is a significant correlation between service quality and visiting interest of mothers at the Kemuning XII Posyandu, Cibeber Village, Cilegon.

pendekatan berkelanjutan dan intervensi berbasis risiko Kesehatan (Kemenkes RI, 2015). Posyandu merupakan salah satu fasilitas yang diberikan pemerintah dalam bidang kesehatan, yang mempunyai tugas memberikan pelayanan kesehatan kepada masyarakat dengan menyelenggarakan proses pengelolaannya mulai dari bayi, balita sampai memberikan pelayanan kepada ibu hamil. Pelaksanaan kegiatan posyandu dilakukan oleh kader dari meja pendaftaran, penimbangan, pengisian KMS dan penyuluhan. 
Sedangkan meja ke lima berupa pelayanan medis dilakukan oleh petugas Kesehatan (Kemenkes RI, 2011).

Faktor factor yang mempengaruhi perilaku kunjungan masyarakat ke posynadu antara lain: faktor pekerjaan orang tua, pengetahuan tentang posyandu, dukungan keluarga dan dukungan tokoh masyarakat (Darmawan. N, 2016).

Study pendahuluan yang telah dilakukan di posyandu Kemuning XII desa Cibeber, didapatkan informasi kunjungan posyandu hanya sekitar $40 \%$ setiap bulannya dari total jumlah 150 bumil atau ibu yang memiliki bayi dan balita di tahun 2020 dalam pemantauan 3 bulan terakhir. Seperti kita ketahui bahwa pada tahun 2020 Indonesia memasuki masa pandemic hingga saat ini, namun pada tahun 2019 didapatkaan informasi data yang serupa terkait jumlah kunjungan posyandu. Oleh karena itu, peneliti melakukan penelitian terkait kualitas layanan serta minat kunjungan posyandu

\section{Metode penelitian}

Metode penelitian yang digunakan adalah dengan menggunakan metode kuantitatif dengan menggunakan menggunakan metode penelitian survey analitik korelatif dengan pendekatan waktu menggunakan cross sectional. Responden penelitian adalah semua ibu yang mempunyai anak balita dengan jumlah 51. Data dianalisis dengan menggunakan analisis bivariat chi square.

\section{Hasil dan Pembahasan}

Hasil penelitian berisi paparan hasil analisis yang berkaitan dengan pertanyaan penelitian. Setiap hasil penelitian harus dibahas. Pembahasan berisi pemaknaan hasil dan pembandingan dengan teori dan/atau hasil penelitian sejenis. Panjang paparan hasil dan pembahasan $40-60 \%$ dari panjang artikel

Hasil penelitian berupa karakteristik responden, data kualitas pelayanan dan minat kunjungan ibu ke posyandu. Data disajikan dalam bentuk tabulasi.
Tabel 1. Distribusi Frekuensi Karakteristik Responden, Kualitas Pelayanan dan Minat Kunjungan ke Posyandu Kemuning XII Desa Cibeber Cilegon

\begin{tabular}{llll}
\hline No & Variabel & F & $\%$ \\
\hline 1 & Kualitas & & \\
& Kurang & 10 & $19.6 \%$ \\
& Baik & 41 & $\mathbf{8 0 . 4 \%}$ \\
2 & Minat & & \\
& Kurang & 11 & $21.6 \%$ \\
& Baik & 40 & $78.4 \%$ \\
3 & Usia & & \\
& <2Otahun & 7 & $13.7 \%$ \\
& $>$ 2Otahun & 44 & $86.3 \%$ \\
4 & Pendidikan & & \\
& $<$ SMA & $\mathbf{2}$ & $3.9 \%$ \\
\hline
\end{tabular}

Berdasarkan tabel 1 menunjukkan bahwa $80.4 \%$ respon menyatakan kualitas pelayanan posyandu baik, dan memiliki minat kunjungan sebesar $78.4 \%$. Responden pada penelitian ini dengan $86.3 \%$ memiliki usia $>20$ tahun, pendidikan $96.1 \%>$ SMA, $62.7 \%$ tidak bekerja, dan memiliki jumlah anak 1 (54\%).

Tabel 2. Hasil Uji Chi Square Hubungan Kualitas Pelayanan Posyandu Dengan Minat Kunjungan Ulang di Posyandu Kemuning XII Desa Cibeber

\begin{tabular}{llllllll}
\hline Minat & \multicolumn{3}{c}{ Kualitas Pelayanan } & \multicolumn{2}{c}{ Total } & P \\
\cline { 2 - 6 } & Kurang Baik & \multicolumn{3}{c}{ Baik } & & \\
\cline { 2 - 6 } Kurang Baik & $\boldsymbol{F}$ & $\boldsymbol{\%}$ & $\boldsymbol{F}$ & $\boldsymbol{\%}$ & $\boldsymbol{F}$ & $\boldsymbol{\%}$ & \\
Baik & 9 & 90 & 1 & 10 & 10 & 100 & 0,000 \\
\hline
\end{tabular}

Berdasarkan tabel 2 menunjukkan bahwa responden yang menyatakan kualitas pelayanan Kurang baik namun memiliki minat kunjungan baik sebanyak $4.9 \%$, dan yang memiliki responden yang menyatakan kualitas layanan baik dan juga memiliki minat kunjungan baik sebanyak $95.1 \%$. Hasil $P$ Value $=0.000$ artinya terdapat hubungan yang signifikan antara kualitas pelayanan dengan minat kunjungan di Posyandu Kemuning XII Desa Cibeber Cilegon.

\section{Kualitas Pelayanan Posyandu Kemuning XII}

Berdasarkan tabel 1 yang menyatakan bahwa distribusi frekuensi dan karakteristik responden berdasarkan kualitas pelayanan diketahui bahwa sebagian besar responden $80.4 \%$ menyatakan kualitas pelayanan baik. Dari hasil pengisian kuesioner tampak bahwa responden mayoritas memilih baik pada point pertanyaan 1,2,4,6,8.9 pada point tersebut lingkup kuesioner berisi fasilitas, kenyamanan, perlengkapan, kebersihan, kerapihan, kemampuan dan kesopanan hal ini dapat memenuhi keinginan atau kebutuhan klien/pasien. Sesuai dengan pernyataaan Wati 
(2010), bahwa Kualitas pelayanan adalah tersedianya fasilitas pelayanan yang bersih, nyaman dapat memenuhi kebutuhan pasien, dan kerapian penampilan petugas. Begitu juga dengan pernyataan Pohan, (2007). Menyatakan bahwa kualitas pelayanan kesehatan memiliki pengaruh terhadap frekuensi kunjungan ibu balita ke posyandu.semakin baik kualitas pelayanan posyandu maka semakin baik pula frekuensi kunjungan ibu balita ke posyandu.

Didukung oleh data karakteristik responden yang pada saat itu hadir di kegiatan posyandu bertepatan dengan kegiatan penyebaran kuesionar, penelitian dilakukan dengan menggunakan teknik accidental sampling (yang kebetulan hadir) didapat bahwa data status pekerjaan $62.7 \%$ tidak bekerja , Handayani,2012 mengatakan bahwa ibu rumah tangga lebih teratur dalam kunjungan posyandu di bandingkan dengan ibu yang bekerja. Hal ini karena ibu rumah tangga labih banyak memiliki waktu lebih banyak diirumah sehingga mereka lebih memperhatikan status perkembangan balitanya dengan cara memeriksakan ke posyandu.

\section{Minat Kunjungan Ke Posyandu Kemuning XII}

Seperti tertulis dalam analisis univariat tabel 1 bahwa minat kunjungan responden ke posyandu sebesar $78.4 \%$, dan sebagian besar responden pada penelitian ini $96.1 \%$ berpendidikan >SMA. Sependapat dengan (Ngastiyah 2005) bahwa tingkat pendidikan menentukan tinggi rendahnya seseorang dalam memahami pengetahuan tentang kegiatan posyandu. Dimana semakin baik tingkat pendidikan orang tua, maka orang tua dapat menerima segala informasi dari luar terutama tenang cara pengasuhan anak dan manfaat kegiatan posyandu. Dilihat dari jenis karakteristik pada penelitian ini, Pendidikanlah yang memiliki persentasi tertinggi, dapat disimpulkan bahwa pendidikan merupakan faktor pendukung dalam tingginya minat kunjungan. Dengan memiliki tingkat pendidikan yang cukup, maka tingkat kemampuan menerima informasi dan memahami pentingnya posyandu pun semakin tinggi. Serta dapat menimbulkan rasa ingin tahu yang lebih tentang kondisi/ pemantauan kesehatan baik ibu, terkait bayi/balitanya berikut pentingnya imunasasi dan informasi seputar kesehatan yang akan disampaikan oleh kader ataupun Nakes.
Jenis pelayanan Posyandu juga memengaruhi ibu balita untuk berkunjung ke Posyandu. Hal ini sesuai dengan penelitian Hardjito K (2015) bahwa 76,3\% ibu balita sangat berminat berkunjung ke Posyandu dengan pelayanan pengembangan/pilihan.

Berikut pernyataan Lestari 2009 menyatakan bahwa jika mutu pelayanan baik, (sudah sesuai standar pelayanan kesehatan) maka tingkat kepuasan juga tinggi, karena semakin tinggi kepuasan maka semakin tinggi pula frekuensi/minat kunjungan). Hal ini terlihat dari hasil pengisian kuesioner yang telah disampaikan. Pada kuesioner yang diberikan,terlihat bahwa pertanyaan pada minat kujungan 1,2 , dan 3 mayoritas diisi dengan kategori baik, sesuai pernyataan Djaali (2013:122) menyimpulkan bahwa minat memiliki unsur afeksi, kesadaran sampai pilihan nilai, pengerahan perasaan, seleksi, dan kecenderungan hati. Minat dapat diekspresikan melalui pernyataan yang menunjukan bahwa pasien lebih menyukai suatu hal daripada hal lainnya, dapat pula dimanifestasikan melalui partisipasi dalam suatu aktivitas.

\section{Hubungan Kualitas Pelayanan dengan Minat Kunjungan Posyandu}

Berdasarkan uji analisis bivariate yang sudah dilakukan, didapatkan bahwa terdapat hubungan antara kualitas pelayanan dengan minat kunjungan dengan nilai Pvalue 0.000 (pvalue $<0.05$ ). Sesuai dengan pernyataan Pohan, (2007). Menyatakan bahwa kualitas pelayanan kesehatan memiliki pengaruh terhadap frekuensi kunjungan ibu balita ke posyandu. semakin baik kualitas pelayanan posyandu maka semakin baik pula frekuensi/minat kunjungan ibu balita ke posyandu. Hal ini sejalan dengan penelitian Hardjito K (2015) yang menyatakan bahwa pelayanan posyandu yang kreatif berpengaruh terhadap minat ibu balita untuk berkunjung ke Posyandu.

Sependapat dengan pernyataan di atas, Handayani (2012) yang menyatakan bahwa pada penelitiannya terdapat hubungan yang signifikan antara kualitas pelayanan dengan frekuensi kunjungan posyandu dengan pvalue $=0.001$. Menurutnya kualitas layanan dapat dipengaruhi oleh beberapa dimensi salah satunya hubungan antar manusia. Demikian juga pada penelitian ini, peneliti dapat menyimpulkan hasil pengisian 
kuesioner responden yang menyatakan hal yang sama dalam pertanyaan 2,6,9 yang hampir secara keseluruhan menyatakan baik. Hubungan baik antar manusia dalam hal ini antara klien/pasien dengan nakes/kader dapat memberikan kenyamanan, didukung oleh sikap sopan dalam memberi pelayanan dan kemampuan memberikan informasi juga sarana komunikasi. Seperti kita ketahui bersama informasi tentang posyandu saat ini sangat mudah diakses baik dari siaran langsung di masjid melalui pengeras suara ataupun media sosial.

Begitu juga dengan pernyataan Lestari (2009) menyatakan bahwa jika mutu pelayanan baik, (sudah sesuai standar pelayanan kesehatan) maka tingkat kepuasan juga tinggi, karena semakin tinggi kepuasan maka semakin tinggi pula frekuensi/minat kunjungan)

\section{Simpulan}

Sebagian besar $80.4 \%$ respon menyatakan kualitas pelayanan posyandu baik, dan memiliki minat kunjungan sebesar $78.4 \%$. Dan terdapat hubungan yang bermakna antara kualitas pelayanan dengan minat kunjungan posyandu kemuning XII di Desa Cibeber Kota Cilegon.

Hasil penelitian tidak sejalan dengan Widiyanto J \& Zebua S (2020) yang menyatakan bahwa minat ibu balita datang ke posyandu bukan karena kualitas pelayanan namun karena ibu balita merasa butuh dan mementingkan tindakan yang diberikan untuk meningkatkan Kesehatan dan tumbuh kembang balitanya.

\section{Ucapan terima kasih}

Terimakasih kepada Responden, Nakes dan Kader yang banyak membantu jalannya penelitian ini, serta Poltekkes Aisyiyah Banten yang telah mendanai penelitian ini dengan pendanaan $R A B$ 2021.

\section{Daftar Pustaka}

Djaali. 2013. Psikologi Pendidikan. Jakarta : Bumi Aksara

Darmawan, Ngurah. 2016. Faktor-faktor Yang Mempengaruhi Perilaku Kunjungan Masysrakat Terhadap Pemanfaatan Pelayanan Posyandu Di Desa Pemecutan Kelod Kecamatan Denpasar Barat. Jurnal Dunia Kesehatan, vol 5, No 2: 29-39.

Gaspersz, Vincent, 2012. All In One: Production and Inventori Management, Edisi 8, Bogor.

Handayani, 2012. Hubungan antara kualitas layanan posynadu dengan frekuensi kunjungan ibu balita di posyandu XI Serangan Sidoluhur Godean Sleman Yogyakarta

Hardjito, K. 2015. Pengaruh Jenis Pelayanan Posyandu terhadap Minat Ibu Balita Mengikuti Kegiatan Posyandu.

Kemenkes RI. 2011. Pedoman Umum Pengelolaan Posyandu. Jakarta: Kemenkes RI.

Lestari, Id, 2009. Hubungan Mutu Pelayanan Kesehatan dengan Tingkat Kepuasan Ibu Balita Pengguna Posyandu di Desa Trimulyo Sleman Yogyakarta

Ngastiyah, 2014. Perawatan Anak Sakit. EGC, Jakarta

Pohan. I, 2007. Jaminan Mutu Layanan Kesehatan (dasar-dasar, pengertian dan penerapan) EGC Jakarta

Wati, 202. Hubungan Mutu Pelayanan Kesehatan Gratis dengan Tingkat Kepuasan Pasien di ruang rawat inap Puskesmas Tengin Baru Kecamatan Sepaku Kabupaten Penajam Paser Utara Provinsi Kalimantan Timur.

Widiyanto, Juli \& Zebua Supryati. 2020. Fakror Eksternal Yang Berhubungan Dengan Minat Ibu Melakukan Kunjungan Ke Posyandu (Studi DI Kelurahan Labuh Baru Timur). Photon Jurnal Sains Kesehatan, Vol 11 (1): 68-77. DOI: https://doi.org/10.37859/jp.v11i1.2423 